\title{
Framing the Conundrum of Total Cost of Ownership of Open Source Software
}

\author{
Maha Shaikh and Tony Cornford \\ London School of Economics and Political Science, Information Systems \\ and Innovation Group, Houghton Street, London WC2A 2AE, UK \\ \{m.i.shaikh, t.cornford\} @lse.ac.uk \\ http://personal.1se.ac.uk/shaikh/, \\ http://personal.1se.ac.uk/cornford
}

\begin{abstract}
This paper reflects the results of phase I of our study on the total cost of ownership (TCO) of open source software adoption. Not only have we found TCO to be an intriguing issue but it is contentious, baffling and each company approaches it in a distinctive manner (and sometimes not at all). In effect it is a conundrum that needs unpacking before it can be explained and understood. Our paper discusses the components of TCO as total cost of ownership and total cost of acquisition (and besides). Using this broad dichotomy and its various components we then analyze our data to make sense of procurement decisions in relation to open source software in the public sector and private companies.
\end{abstract}

Keywords: open source software, total cost of ownership, benefits, exit costs, software adoption.

\section{Introduction}

Total cost of ownership (TCO) is considered to be a fundamental issue when making software procurement decisions [1-4] in organizations yet this is an area that has received limited attention. In this paper we are concerned with TCO but more specifically in relation to open source software (OSS) adoption decisions by organizations ${ }^{1}$. This adds yet another layer of complexity because the assessment of open source software procurement is not exactly the same as that for proprietary software [5]. Indeed, we find that by unpacking the idea of open source TCO we become more aware of the taken for granted in proprietary software procurement decisions. TCO has been defined as an understanding of "the "true cost" of doing business with a particular supplier for a good or service' [6]. The idea of a 'true cost' and the ability to be able to assess it accurately, however is something most academics and practitioners would agree is not straightforward [7]. Thus we prefer a definition of TCO offered by Lerner and Schankerman [8] which distinguishes between different costs, and TCO is

${ }^{1}$ Our research is funded by the UK Cabinet Office and the OpenForum Europe. The aim of this research is to assess the various costs and value of open source adoption by the public sector and private organizations. 
understood as the total cost of providing a functionality using one program. The proper accounting of cost should include total costs of procurement, management and support, associated hardware costs, and when one is thinking of changing software solutions, migration costs' (p107). In this definition we have a range of costs mentioned, all of which need attention before any true grasp of TCO of software can be reached.

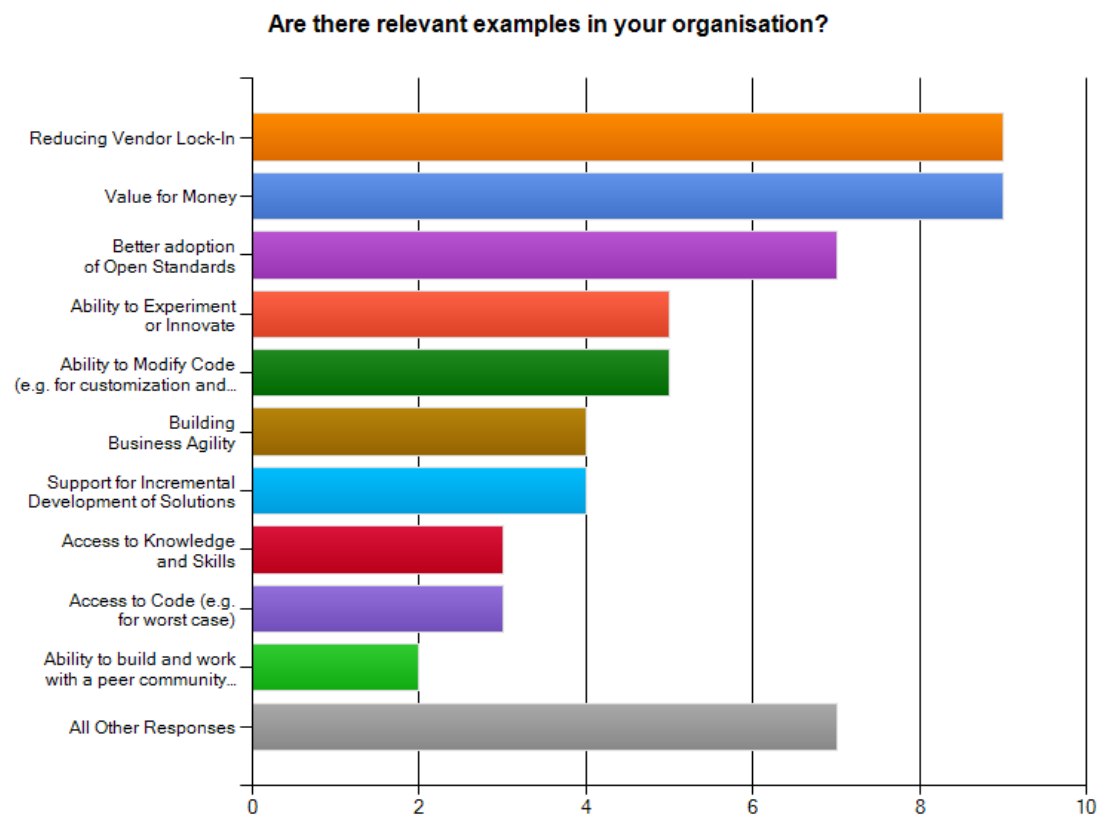

Fig. 1. This figure shows the various factors companies in our pro-forma considered when making a decision to move to open source, and the relative weight of each factor

Some authors claim that there is no such thing as 'the cost of software' [8] implying that cost is a more multi-faceted issue which needs to be understood better. Thus, like all evaluation decisions TCO has a quantitative and qualitative element. In section 3 below we detail the various elements of each type of cost that we have noted from literature and from our data. We found this to be a recognized issue amongst practitioners in the public sector and the private. Most decisions taken on procurement in either sector are understandably based on cost but this is not the only factor and with open source software, we found that this is not even the most relevant. The larger concern for companies eager to adopt open source software was reduced vendor lockin, and what companies understood as 'value for money' (see Fig 1).

Lerner and Schankerman [8], with their distinctions in costs, indicate the conundrum of TCO. Companies are becoming more aware of these issues but the smaller ones do not have the resources to actually carry out a full detailed TCO study. How 
does a company assess the softer costs [9] surrounding software procurement especially when the software is open source (a relatively less familiar category for many companies)? It is important to make sense of the categories of cost and exactly what they entail to better manage them and make better informed decisions.

\subsection{Conundrum of TCO of OSS}

Literature in the area of TCO provides some useful models of cost evaluation [10]. What interests us in this study is not only the quantifiable costs but the more amorphous expense that occurs at the start, operation and even migration away from the software adoption. Business analysts [11-13] in this area have made note of the many possibilities that open source offers companies [14] but again these are hard to quantify, and often for smaller companies this is a consideration for the future. Most small companies that adopt open source software do so with the intention of cutting back on license costs (as the license cost of OSS is zero or close to it) $[10,15]$. However, the total cost of ownership is not the same as the total cost of acquisition, or the cost of operation, and this is the space we want to explore with our study. This categorization is necessary as this has temporal consequences for adoption of software.

The total cost of acquisition usually refers to the costs that are needed to bring the software to the actual point of use, so theoretically it includes the cost of software (buying it). The total cost of operation is more nuanced a cost but very relevant in the open source domain where companies need to adjust their TCO models to take into account the different areas of expense that OSS involves. Operational costs refer to the policies in place in companies that encourage and aid open source adoption, and very importantly, clear and structured TCO assessments before making procurement decisions.

In this paper we explore the various forms of costs that are necessary for companies and the public sector to explore in detail before making any procurement decisions, but especially those related to open source as this is a relatively new concept for them and different in that the license cost is very low yet other costs seem to mount (but are often ignored and not understood).

\section{Methodology}

This study is structured to take place in two phases. This paper reflects some of the results from phase I which includes a data collection pro-forma of twenty-five questions. These questions cover the basics of the company size, name and focus, but then go on to ask some very detailed questions about the various applications that are open source, why they were chosen, if they replaced proprietary software, was any difference in cost experienced, and finally, what prompted this change or need to adopt open source software. The responses to the pro-forma, especially to the last question will be fed into an interview guide. This then takes us to phase II where we aim to 
conduct between 35-40 in-depth interviews. Access in a number of organizations that responded to the pro-forma has already been negotiated and phase II will take place over the summer of 2011.

\subsection{Phase I - Pro-Forma}

Phase 1 involved the creation of the pro-forma which was based on literature and documentation that helped to understand TCO models used in companies. The proforma was used as an early and simple data collection device rather than a fully structured and detailed survey. Our study is more qualitative in approach so the pro-forma was meant simply to gather material to help us set-up interviews, gain access and get some early comments to amend our interview guide. The pro-forma does not ask for facts, and figures on TCO for each organization, instead we ask the respondents to reply in relation to a Likert scale of 1-5.

The pro-forma was set up for access in two ways, document form (available in odt, pdf and doc formats) and an online version set up in SurveyMonkey. The aim of this study is to make sense of adoption of open source software by both private companies and public sector organizations. Though funded by the UK Cabinet Office to assess and evaluate the costs and issues involved in open source adoption by government agencies we decided that a more sound methodology would involve a balanced mix of commercial and public sector organizations. Public sector organizations are not profit orientated yet there is much to learn from private companies and their manner of dealing with open source. The larger idea here is the level of experience and comfort that private companies bring to open source adoption which is sorely lacking in the public sector. There are some exemplary cases of open source adoption by the public sector like the Extremadura case in Spain [16, 17] but there are far more 'success' stories of open source adoption by commercial companies [18-21]. The factors that encourage private companies to adopt open source software, especially considering most business models of such adoption indicate that the software itself does not lead to value creation or capture directly [22-25], make some of the lessons translatable across both sectors.

The pro-forma was put online for a period of two months (and is still online but for the sake of this paper we only took into account the pro-formas completed in the first two months) and we received twenty-four responses. We also received seven paper based pro-formas sent back to us as scanned documents via email. This made a total of thirty-one pro-formas. We had set the pro-forma to ensure that details of the respondent was a required category. This was done to be able to filter out any responses that were biased, duplicate or simply not completed with any seriousness. Of the 24 online pro-formas two were filled in by people calling themselves 'test' and 'anonymous'. We discounted the results from both these pro-formas. We also had two incomplete pro-formas online. Incomplete pro-formas were those where some questions were skipped. As this exercise was carried out as a precursor and data gathering exercise more for the interest of creating a strong and clear interview guide for phase II we accepted the results of the incomplete pro-formas. Phase II is where the 
researchers involved in this study hope to gain a more detailed understanding of TCO models and the decision-making process in organizations so it was felt that so long as the pro-formas were recognized to be valid (not anonymous or biased) and useful (filled in $75 \%$ of the pro-forma and added some non-mandatory comments that helped us to evaluate the experience of the company with open source) we would include the results to help shape the interview guide for phase II.

The pro-forma has four sections. The aim of section one is to ask for simple information like the name and affiliation of the respondent. This includes the size and name of the company/local authority. Section two prompts for the sort of OSS used by the organization and the time span of use. The aim of section three is to gather details on strategic drivers that lead to OSS adoption, and section 4 is concerned with eliciting the TCO models used.

\subsection{Phase I Leading to Phase II}

Of the total pro-formas we received the majority of them were filled in by small to medium sized private companies (44\%). Small to medium sized enterprises included all those with a number of employees ranging between 1-100. We had $24 \%$ of the pro-formas completed by employees of large, and in many cases global companies (employees ranging from 101 and above). Public sector replies made 32\% of the total. In phase II we intend to cover a larger portion of the public sector.

The pro-forma had a number of questions where respondents were asked to add comments or spell out the category of 'other' in more detail. Responses to such questions gave rise to some very interesting issues which will become a part of the interview guide and informed the researchers involved. The respondents for the pro-forma were asked for their contact details and phase II will draw us back to the those that made very intriguing comments. Phase II will involve in-depth interviews focused on 5-7 case studies. Key personnel involved in making procurement decisions and strategy of open source use in the organization will be interviewed.

The cases will be chosen on the basis of whether there has been involvement with open source adoption, use and/or redistribution for at least a period of two years. This is to ensure that there has been time enough for reflection on the process and there are some indicators that show 'success' or 'failure' - more simply, is open source still being used, has the use of it increased over time, and has it spread up the stack. We also want an even mix of public and private organizations to make it possible to reflect across the cases and build on lessons learned for an exchange of ideas. The organizations and their experience with open source needs to have been fruitful at some level but we are equally aware that we need to have examples of less successful implementations as this will enrich our work and understanding of the concerns with open source that can be faced. Indicators for the less successful cases include a return to proprietary software use, move to outsourcing their software development and a shrinkage in their in-house IT department. And lastly, our cases will include local authorities in the UK and other European government as well such as the Municipality of Munich, Municipality of Andalucía. 


\section{Analysis and Discussion}

The pro-forma results are very interesting and we only have space to share some of the key ideas that emerged. These ideas include the importance of liberty [15] and flexibility (reduced vendor lock-in) provided by open source to companies and the public sector, that long term costs vary far more across companies considering their size and experience with open source, short term costs are slightly higher, that most companies choose a combination of open source and proprietary software where their decisions are based on pragmatism and need rather than questions of openness.

In this section we take these broad themes and frame them in relation to another interesting dimension that we noted from our data, that of a more fine-tuned TCO categorization than has been offered so far by other studies. We found that the cost categories were not limited to two broad ones, cost of acquisition and cost of operation, but instead we recognized two other very key cost factors that companies are beginning to take very seriously in relation to open source software procurement decisions - cost of adoption and exit costs (see Table 1).

The cost of operation and software are more quantifiable and thus easier to measure and evaluate. Cost of operation includes the expense of conducting a TCO study before making a decision of implementation. This is similar for proprietary software so in some respects this is not specific to open source, but rather to software decisions in general. The cost of software includes the cost of the license, setting up costs, and other costs which are similar to the cost of operation in their lending themselves to be quantified. However, the cost of adoption and exit costs for open source pose some interesting challenges but also opportunities.

\subsection{Cost of Adoption}

The cost of adoption, we found, concerns all the relevant but more qualitative expenses involved with the broad idea of adoption such as the learning necessary when you adopt open source for the first time or for a new part of the stack (see Table 2). Very importantly it also includes interoperability costs which many companies surprisingly ignore even though this is a feature of proprietary software as well. The difference with open source is that some respondents stated that they feel they can make the

Table 1. Different Categories of TCO, and what each involves

\begin{tabular}{|c|c|c|c|}
\hline \multicolumn{5}{|c|}{ Categories of TCO } \\
\hline Cost of operation & Cost of software & Cost of adoption & Exit costs \\
\hline Formal TCO assessment & Initial purchase price & Learning & Migration costs \\
\hline TCO policy & $\begin{array}{c}\text { Monetary costs of set- } \\
\text { up }\end{array}$ & Interoperability & Re-training \\
\hline $\begin{array}{c}\text { Cost of evaluating } \\
\text { software (tinkering) }\end{array}$ & $\begin{array}{c}\text { Customization } \\
\text { expense }\end{array}$ & Support services & Switching costs \\
\hline & Software scaling cost & Training & \\
\hline & & Access to upgrades & \\
\hline & & & \\
\hline
\end{tabular}


necessary adjustments because the code is open, yet as we are becoming more aware, there is a steep learning curve with all software not created in-house. Upgrades are a growing concern for companies with open source because most open source software tends to adapt and be changed more frequently than proprietary. Of course the choice to upgrade is with the user yet interoperability can also become a problem if one software is upgraded but other applications and infrastructure are not.

\subsection{Exit Costs}

Exit costs are yet a more intriguing idea. Respondents agreed that this aspect was the most ignored and yet it formed a very positive aspect of the overall TCO of open source adoption. Table 2 outlines the areas where the costs with open source were considered to be the lowest but take note of the 'other' category in Table 2 and Figure 2. Upon reading the comments added by the respondents it was evident that though open source saved the organization money there were costs that had been ignored and ill-understood.

Exit costs include all the expenses of switching from one software to another, various interoperability expenses, costs related to legacy systems, retraining staff and initial teething issue costs. This is an area where at least at present companies feel that open source costs are higher and not clear at all. The low license costs with open source software, according to the respondents though very real can become misleading because companies simply begin to base their decisions on that cost alone and dismiss any other factor.

Table 2. Areas and applications of OSS which Saved Money for Organizations

\begin{tabular}{lrrrr}
\hline \multicolumn{4}{c}{ Which OSS saved your organization money? } \\
\hline $\begin{array}{l}\text { Agree } \\
\text { Applications: }\end{array}$ & $\begin{array}{c}\text { Agree some- } \\
\text { what }\end{array}$ & $\begin{array}{c}\text { Completely } \\
\text { disagree }\end{array}$ & $\begin{array}{l}\text { No change } \\
\text { in expense } \\
\text { - same }\end{array}$ \\
$\begin{array}{l}\text { Enterprise } \\
\text { systems }\end{array}$ & $\mathbf{7 5 . 0 \%}$ & $12.5 \%$ & $0.0 \%$ & $6.3 \%$ \\
$\begin{array}{l}\text { Vertical/line of } \\
\text { business }\end{array}$ & $\mathbf{7 1 . 4 \%}$ & $0.0 \%$ & $0.0 \%$ & $0.0 \%$ \\
$\begin{array}{l}\text { Desktop } \\
\text { System's De- }\end{array}$ & $\mathbf{5 8 . 3 \%}$ & $0.0 \%$ & $0.0 \%$ & $0.0 \%$ \\
$\begin{array}{l}\text { velopment } \\
\text { Infrastructure: }\end{array}$ & $\mathbf{8 4 . 6 \%}$ & $7.7 \%$ & $0.0 \%$ & $0.0 \%$ \\
$\begin{array}{l}\text { OS Platforms } \\
\text { Application }\end{array}$ & $\mathbf{7 1 . 4 \%}$ & $7.1 \%$ & $0.0 \%$ & $7.1 \%$ \\
$\begin{array}{l}\text { Servers } \\
\text { Web services }\end{array}$ & $\mathbf{8 4 . 6 \%}$ & $7.7 \%$ & $0.0 \%$ & $0.0 \%$ \\
$\begin{array}{l}\text { Networking } \\
\text { Database }\end{array}$ & $\mathbf{8 8 . 2 \%}$ & $11.8 \%$ & $0.0 \%$ & $0.0 \%$ \\
Other & $\mathbf{8 4 . 6 \%}$ & $0.0 \%$ & $0.0 \%$ & $7.7 \%$ \\
\hline
\end{tabular}


However, when migrating between one open source product to another the migration costs are then lower because open source is based on open standards and there is greater interoperability. Most companies that had a more long term understanding of their software adoption added comments in the pro-forma to the effect that the migration costs (exit costs) were more favourable for open source and so this became one of the deciding factors in favour of OSS. Simply put, migration costs between one proprietary application to another are always considerable as neither products are open and it is thus difficult to manage the necessary interfacing and interoperability changes across all the software applications that need to 'speak to each other'.

\subsection{Vendor Lock-in and Lock-Out}

Vendor lock-in though a real problem with proprietary software is less so with open source. This may well be a real consideration yet what we note from our study so far is that expertise of the software (be it open source or otherwise) and a lack of good documentation which is a problem with open source often becomes a lock-out. Companies feel discouraged from adopting any software they cannot control [29], but also cannot obtain comprehensive services and troubleshooting. The idea of reaching out to an unknown community [26] has a romantic appeal but is not practical.

Indeed, such promises spread FUD about open source adoption and lead to lockout because companies avoid anything they are not familiar with. It is easy enough in theory to take code and customize it yet as many respondents noted this is not so in practice. They are forced to hire experts and look for support to communities outside the company. This is a drain on their resources and an expense that was not considered by the decision takers, even if a TCO assessment was carried out before procurement decisions were taken. This would not be such an issue if the software is vendor-supported, however, we have found that many companies and local authorities are drawn to open source because they wish to control the software source and make changes to it both in-house and with the help of a strong external community.

\subsection{Temporal Element of TCO}

Another key theme that arose from our pro-forma data was that of cost temporality. Of the four costs outlined in Table 1 the cost of adoption and exit costs are relatively quite high for open source software. This is even more marked with the added complexity of the size and experience of the organization. If the company is large and experienced with open source then these two costs are often well-understood and thus less expensive. Large companies can diversify and absorb costs better than smaller companies and this is largely true for the public sector as well. Smaller organizations however usually jump on the open source bandwagon with the naive idea that this will prove cheaper. They have also not undertaken a TCO analysis and if they are not experienced with open source it was then found that the expense of open source surprised many. In some cases, especially in the public sector (coupled with issues of poor interoperability) we have seen a return to proprietary software. Phase II of our study will include this local authority as a full case study to better explore the problems, issues and dilemmas that forced it to return to closed source software adoption. 


\subsection{Pragmatism and the Idea of Value}

Most companies, like software developers and hackers work on the basis of pragmatism. If something is good enough and not broken then it will be continued to be used. Open source requires some experience and practice and very key, the licenses involved with open source need good skills and expertise, something most small companies do not have the resources for and the public sector simply does not consider. In effect if something is good enough then change is considered problematic and unnecessary. In the public sector in the UK we have found that local authorities are beginning to gravitate towards open source simply because of the lower costs promised by open source (due to the recession), however a better understanding of the benefits of

Please briefly list principal open source software (OSS) that is implemented in the organisation

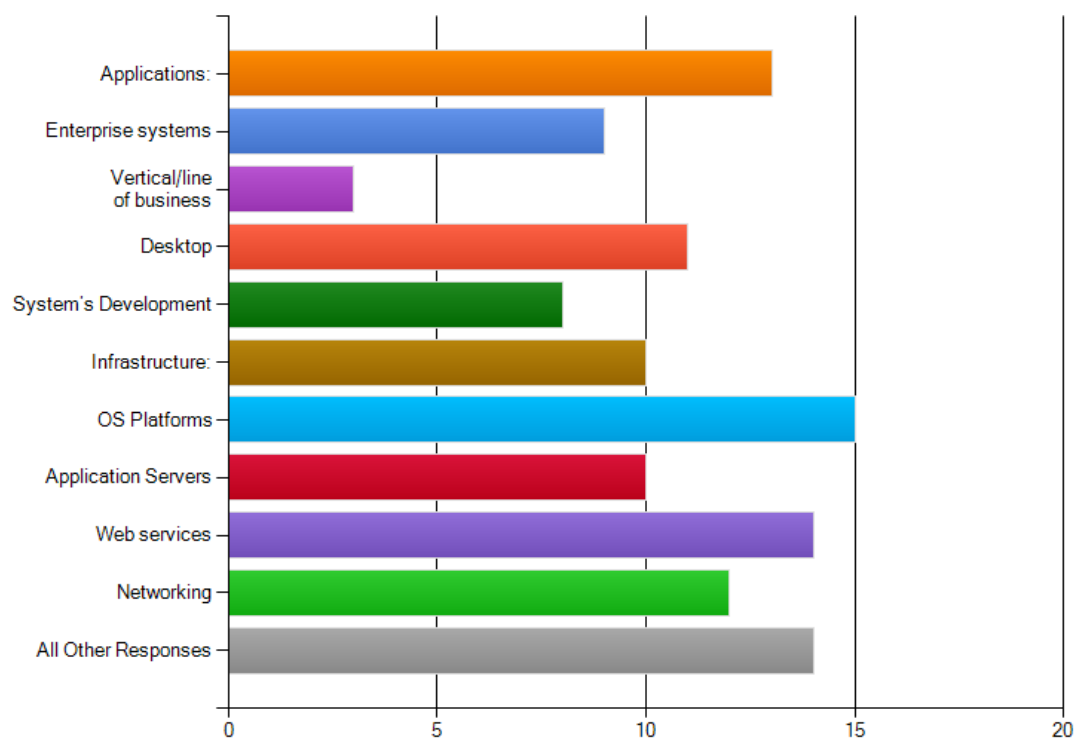

Fig. 2. This figure shows the various open source software concentration in implementation in the different organizations

open source is needed. The idea of where the value lies in open source software adoption is the needed. And by value we do not mean a monetary value (though it does include this category) we refer to the softer side of benefits - that of flexibility, openness, freedoms, ability to tweak and customize and along with open standards and open data - a far more open and accessible software environment. This is where the true benefits and cost reductions will come in the future.

The real value in open source adoption is clearly the collaborative co-creative ideology and spirit it encourages. This in turn leads to value creation, innovation, and a stronger ecosystem [27]. 


\section{Conclusion}

This paper maps the initial stages of our study of the total cost of ownership of open source software. The analysis provides some interesting answers to broad questions about cost but more importantly it raises relevant questions about the rather enigmatic quality of assessing the total cost of software, especially open source software. It is a conundrum as most companies lack experience with open source and more to the point, a slightly different understanding of 'value for money' is needed. The actual monetary cost of open source software adoption in many cases is not unlike that of proprietary software but it is the liberties, flexibility and control that it provides that draws companies and the public sector towards it.

Phase I of our study has given rise to some very interesting findings. The main ideas the respondents focused on included the lack of maturity level of open source software, license confusions and lack of knowledge about the implications of various open source licenses. Other ideas which arose were somewhat more surprising, most organizations do not even attempt a TCO study before making procurement decisions because of the expense such studies involve. The models used to assess TCO are also more suited for proprietary software and companies are not comfortable or skilled to tweak them for open source. And lastly, there is no policy in most companies for open source adoption. These decisions are made more ad-hoc and usually based on pragmatic decisions of use and need rather than cost.

However, there is much detail yet to be teased out in this amorphous area, and during the course of this study we hope to be able to show more clearly where the large part of the costs lie with open source software adoption, exactly where and how they are distinctive in comparison to proprietary software, what strategies and practices the public sector and companies can employ to make more effective use of the unique qualities of open source so that the software can yield a stronger feeling of 'value for money'. Indeed, can we go so far as to suggest that open source software adoption is an idea that the public sector not only needs to explore more seriously but in fact it will prove more effective, valuable, cheaper and necessary in the future? We aim to be able to provide a more nuanced answer to this and other questions at the end of our study, and encourage other researchers to explore such aspects because we feel that public sector adoption of open source has the potential to have real influence on open government strategies [28], open standards, and open data.

\section{References}

1. Ellram, L.M.: A Taxonomy of Total Cost of Ownership Model. Journal of Business Logistics 15, 171-191 (1994)

2. Ellram, L.M.: Total cost of ownership an analysis approach for purchasing. Journal of Physical Distribution and Logistics 25, 4-23 (1995)

3. Ellram, L.M., Siferd, S.P.: Total Cost of Ownership: A Key Concept in Strategic Cost Management Decisions. Journal of Business Logistics 19, 55-84 (1998)

4. Hurkens, K., van der Valk, W., Wynstra, F.: Total Cost of Ownership in the Services Sector: A Case Study. The Journal of Supply Chain Management 42, 27-37 (2006) 
5. MacCormack, A.: Evaluating Total Cost of Ownership for Software Platforms: Comparing Apples, Oranges, and Cucumbers. AEI-Brookings Joint Center for Regulatory Studies Series (2003)

6. Ellram, L.M.: A Framework for Total Cost of Ownership. The International Journal of Logistics Management 4, 46-60 (1993)

7. Wouters, M.J.F., Anderson, J.C., Wynstra, F.: The Adoption of Total Cost of Ownership for Sourcing Decisions - A Structural Equations Analysis. Accounting, Organizations and Society 30, 167-191 (2005)

8. Lerner, J., Schankerman, M.: The Comingled Code: Open Source and Economic Development. MIT Press, Hong Kong (2010)

9. Carr, L.P., Ittner, C.D.: Measuring the Cost of Ownership. Journal of Cost Management 6, 42-51 (1992)

10. Russo, B., Succi, G.: A Cost Model of Open Source Software Adoption. In: IJOSSP, pp. 60-82 (2009)

11. Sutor, R.: Managing open source adoption in your IT organization (2009), http: / /www. sutor.com/newsite/blog-open/?p=3260

12. Galoppini, R.: Open Source TCO: Total Cost of Ownership and the Fermat's Theorem (2009), http://robertogaloppini net/2009/01/08/open-source-tcototal-cost-of-ownership-and-the-fermats-theorem/

13. Burkhardt, R.: Seven Predictions for Open Source in (2009), http://it.syscon. com/node/797241

14. Wheeler, D.A.: Why Open Source Software / Free Software (OSS/FS, FLOSS, or FOSS)? Look at the Numbers (2007), http: / / www.dwheeler.com/oss_fs_why.html

15. Phipps, S.: Open Source Procurement: Subscriptions. In: Computer World, UK (2011)

16. Zuliani, P., Succi, G.: Migrating public administrations to open source software. In: Esociety IADIS International Conference, Avila, Spain, pp. 829-832 (2004)

17. Zuliani, P., Succi, G.: An Experience of Transition to Open Source Software in Local Authorities. In: e-Challenges on Software Engineering, Vienna, Austria (2004)

18. Dinkelacker, J., Garg, P., Miller, R., Nelson, D.: Progressive Open Source, HewlettPackard, Palo Alto, California HPL-2001-233 (September 28, 2001)

19. Dahlander, L.: Penguin in a newsuit: a tale of how de novo entrants emerged to harness free and open source software communities. Industrial and Corporate Change 16, 913-943 (2007)

20. Fitzgerald, B.: The Transformation of Open Source Software. MIS Quarterly 30, 587-598 (2006)

21. O’Mahony, S., Diaz, F.C., Mamas, E.: IBM and Eclipse (A), Harvard Business Review Case Study, December 16 (2005)

22. West, J., Gallagher, S.: Challenges of Open Innovation: The Paradox of Firm Investment in Open Source Software. R\&D Management 36, 315-328 (2006)

23. West, J.: How Open is Open Enough? Melding Proprietary and Open Source Platform Strategies. Research Policy 32, 1259-1285 (2003)

24. Osterwalder, A., Pigneur, Y., Tucci, C.L.: Clarifying Business Models: Origins, Present, and Future of the Concept. Communications of the Association for Information Systems 15, 1-40 (2005)

25. Vargo, S.L., Lusch, R.F.: Evolving to a New Dominant Logic for Marketing. Journal of Marketing 68, 1-17 (2004)

26. Agerfalk, P., Fitzgerald, B.: Outsourcing to an Unknown Workforce: Exploring Opensourcing as a Global Sourcing Strategy. MIS Quarterly 32, 385-400 (2008) 
27. Shaikh, M., Cornford, T.: Understanding Commercial Open Source as Product and Service Innovation. In: 2011 Academy of Management Annual Meeting, San Antonio, Texas, USA (2011)

28. Noveck, B.S.: Defining Open Government (2011), http: / / cairns. typepad.com/blog/2011/04/whats-in-a-name-opengov-we-gov-gov-20-collaborative-government.html

29. Shaikh, M., Cornford, T.: Letting Go of Control to Embrace Open Source: Implications for Company and Community. In: The Hawaii International Conference on System Sciences (HICSS), Koloa, Kauai, Hawaii, USA, vol. 43 (2010) 